Int. J. Dev. Biol. 49: 881-884 (2005)

doi: 10.1387/ijdb.052011he

Developmental Expression Pattern

\title{
Xenopus laevis FoxE1 is primarily expressed in the developing pituitary and thyroid
}

\author{
HEITHEM M. EL-HODIRI ${ }^{1,2}$,* , DANIEL W. SEUFERT ${ }^{1}$, SRIVAMSI NEKKALAPUDI ${ }^{1}$, NICHOLE L. PRESCOTT1 \\ LISA E. KELLY ${ }^{1}$ and MILAN JAMRICH ${ }^{3}$ \\ ${ }^{1}$ Center for Molecular and Human Genetics, Columbus Children's Research Institute, Columbus, OH, USA, ${ }^{2}$ Department of Pediatrics, \\ School of Medicine and Public Health, Ohio State University, Columbus, OH, USA and ${ }^{3}$ Departments of Molecular and Cellular Biology and \\ Molecular and Human Genetics, Baylor College of Medicine, Houston, TX, USA
}

\begin{abstract}
The members of the FoxE subfamily of Fox (forkhead) genes are expressed in the developing pituitary, thyroid and lens. Mammalian Foxe1 is expressed primarily in the developing pituitary and thyroid gland, Foxe3 is expressed in the developing lens, while Xenopus FoxE4 is expressed in the developing lens and thyroid. Here we report the identification of Xenopus FoxE1, a gene that is primarily expressed in the developing pituitary and thyroid.
\end{abstract}

KEY WORDS: forkhead, FoxE1, pituitary, thyroid, TTF-2, Xenopus

Fox proteins (also known as forkhead, or winged helix proteins) comprise a family of transcription factors containing the winged helix DNA binding motif. Many of these gene products are involved in regulation of gene transcription during development and several developmental disorders in humans are caused by mutations in Fox genes (Carlsson and Mahlapuu, 2002, Hromas and Costa, 1995, Kaufmann and Knochel, 1996). Members of the FoxE subfamily of Fox genes are expressed in the developing anterior ectoderm and endoderm (Blixt et al., 2000, Brownell et al., 2000, Dathan et al., 2002, Kenyon et al., 1999, Yu et al., 2002, Zannini et al., 1997). This subfamily includes mammalian Foxe1 (thyroid transcription factor 2 or TTF-2), Foxe 3 and Xenopus FoxE4 (Xlens 1). Foxe1 is expressed in several developing ectodermal and endodermal derivatives of the head including the thyroid, Rathke's pouch, tongue, esophagus, epiglottis, pharynx, whiskers and nasal choanae (Dathan et al., 2002, Zannini et al., 1997). Foxe 3 is primarily expressed in the developing lens ectoderm (Blixt et al., 2000, Brownell et al., 2000). In Xenopus, FoxE4 is expressed in the lens ectoderm and the developing thyroid (Kenyon et al., 1999). A recently identified Amphioxus FoxE4 ortholog, AmphiFoxE4, is expressed in a region of the pharyngeal endoderm called the club-shaped gland and not in the endostyle, the $A m$ phioxus thyroid homologue (Yu et al., 2002). We isolated a cDNA encoding the Xenopus laevis FoxE1 protein by degenerate PCR (Fig. 1). The most similar mammalian homologue is Foxe1 (45.8\% identity), also known as thyroid transcription factor 2 (TTF2) (Zannini et al., 1997). However, there are notable differences between Xenopus FoxE1 and mouse Foxe1 (Fig. 1A). Notably,
FoxE1 lacks the polyalanine repeats found in Foxe1, associated with transcriptional repression and mutated in patients with thyroid dysgenesis (Hishinuma et al., 2001), indicating that FoxE1 may be functionally distinct from Foxe1. FoxE1 is also closely related to Xenopus laevis FoxE4. Although FoxE1 and FoxE4 have highly similar forkhead domains, there are many differences outside of the forkhead domain ( $44.9 \%$ identity), confirming that they represent distinct gene products. To investigate the spatio-temporal expression pattern of FoxE1, whole mount in situ hybridizations were performed using Xenopus laevis embryos spanning a variety of embryonic stages. FoxE1 expression is first observed at late neural tube and early tailbud stages in a discrete area on the anterior face of the embryo, corresponding to the position of the hypophyseal placode (Fig. 2A-D). FoxE1 expression continues in the developing pituitary at late tailbud stages (Fig. 2E,F). At these stages, the expression of FoxE1 is very similar to the expression pattern of Xanf2 (Mathers et al., 1995) and POMC (Holling et al., 2000) (Fig. 2H,I). Expression of FOXE1 precedes expression of $P O M C$ and is preceded by Xanf2 expression in the anterior neural. As development progresses, FoxE1 is expressed in the mesoderm of the branchial arches (Fig. 2E,F,N). FoxE1 is expressed in the developing thyroid at st 38 (Fig. 2J,M), as is $N k \times 2.1$ (also known as thyroid transcription factor 1) (Hollemann and Pieler, 2000, Small et al., 2000) (Fig. 2K,O) and FoxE4 (Kenyon, Moody et al., 1999) (Fig. 2L). FoxE1 is also expressed in the pharyngeal

Abbreviations used in this paper: TTF, thyroid transcription factor.

\footnotetext{
*Address correspondence to: Dr. Heithem El-Hodiri. Center for Molecular and Human Genetics, Columbus Children's Research Institute, 700 Children's Drive, Columbus, OH 43205. Fax: +1-614-722-2817. e-mail: elh@ccri.net
} 


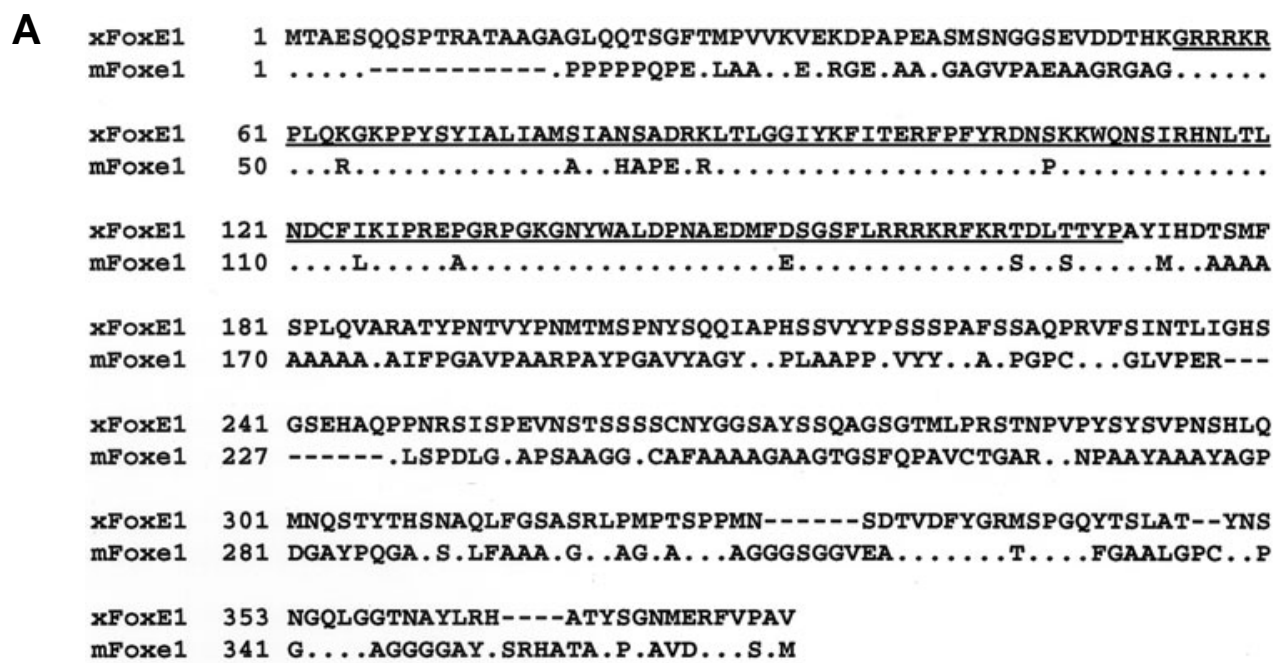

B FOXE1 1 GGRRRKRPLQKGKPPYSYIALIAMSIANSADRKLTLGGIYKFITERFPFYRDNSKKWQN

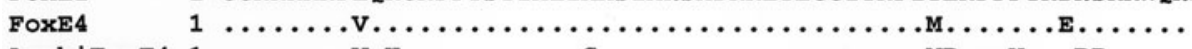

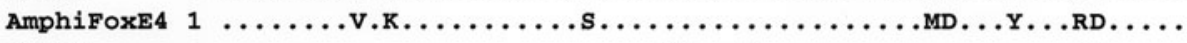

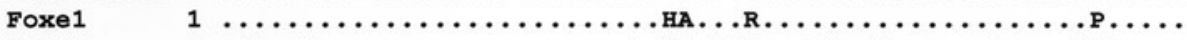

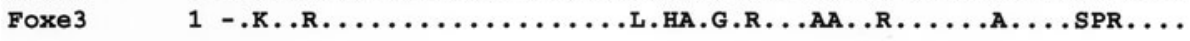

FOXE1 61 IRHNLTLNDCFIKIPREPGRPGKGNYWALDPNAEDMFDSGSFLRRRKRFKRTDLTTYP

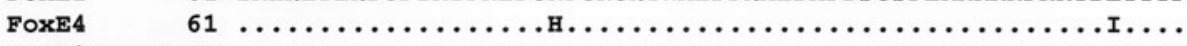

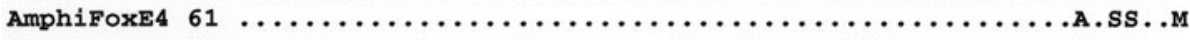

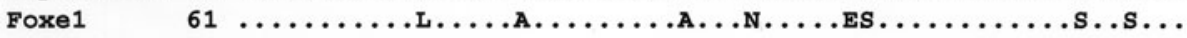

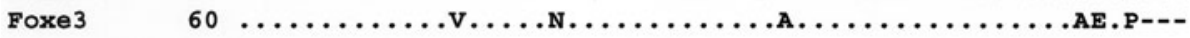

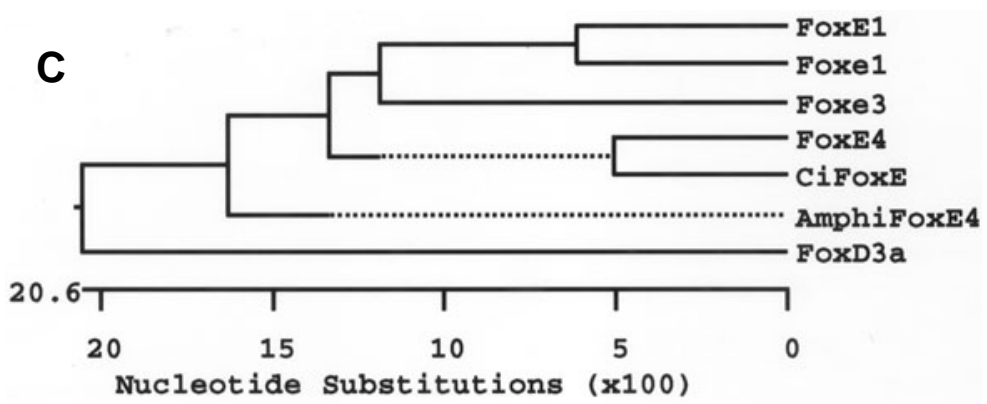

D

\begin{tabular}{|c|c|c|c|c|c|c|c|c|}
\hline \multicolumn{4}{|c|}{ Percent } & Iden & Eity & & & \\
\hline 1 & 2 & 3 & 4 & 5 & 6 & 7 & & \\
\hline & 44.9 & 45.8 & 42.0 & 36.1 & 29.6 & 36.8 & 1 & \\
\hline & & 33.7 & 43.1 & 41.1 & 31.0 & 38.1 & 2 & FoxE4 \\
\hline & & & 49.3 & 34.2 & 24.8 & 33.7 & 3 & Foxe1 \\
\hline & & & & 37.2 & 35.1 & 37.8 & 4 & Foxe3 \\
\hline & & & & & 27.5 & 34.1 & 5 & AmphiFoxE4 \\
\hline & & & & & & 27.8 & 6 & FoxD3a \\
\hline & & & & & & & 7 & CiFoxE \\
\hline
\end{tabular}

Fig. 1. Comparison of amino acid sequences of FoxE1 and other related forkhead gene products. (A) Predicted amino acid sequence of FoxE1 aligned with mouse Foxe1. Forkhead domain is underlined. Dots indicate identical amino acids. Dashes indicate spaces inserted into sequence to aid spacing during alignment. (B) Alignment of forkhead boxes (B) of FoxE1 and related genes Foxe 1 (NP_899121), Foxe3 (AAF15997), Xenopus laevis FoxE4 (AAF20385) and Amphioxus AmphiFoxE4 (AAK85731). (C) Phylogenetic analysis of Xenopus laevis FoxE4 and FoxE5, mouse Foxe1 and Foxe3, AmphiFoxE4 (AAK85731), Ciona FoxE (BAC57420) and Xenopus laevis FoxD3a (BAA36334) was performed from ClustalWalignment using the MegAlign program (DNAStar, Inc). (D) Pairwise percent amino acid identities of Xenopus laevis FoxE1 and FoxE4, mouse Foxe1 and Foxe3, AmphiFoxE4, CiFoxE and FoxD3a were calculated from ClustalW alignment using the MegAlign program (DNAStar, Inc). 


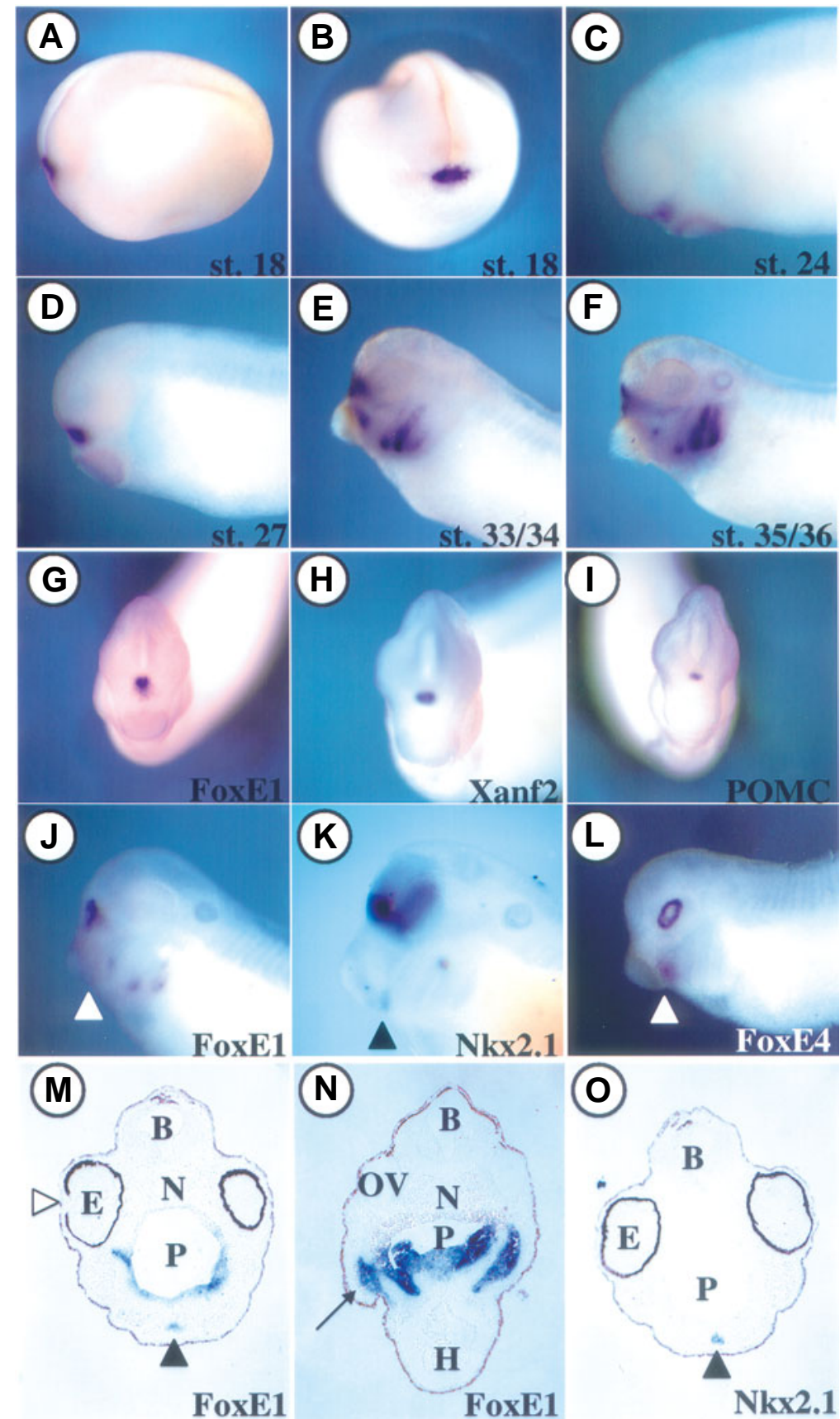

Fig. 2. Expression of FoxE1 in Xenopus embryos. (A-F) Lateral (A,C-F) and anterior $(B)$ views of whole mount in situ hybridized with antisense probe for FoxE1. (A,B) Stage 18, (C) Stage 24, (D) Stage 27, (E) Stage 33/34 and (F) Stage 35/36. (GL) Comparison of FoxE1 expression with markers of the pituitary $(\mathbf{H}, \mathbf{I})$ and thyroid development (K,L). (G) Anterior view of a st 35/36 embryo hybridized with FoxE1. $\mathbf{( H , I ) ~ A n t e r i o r ~ v i e w s ~ o f ~ t a i l b u d ~ s t a g e ~ e m b r y o s ~ h y b r i d i z e d ~ w i t h ~ a n t i s e n s e ~ r i b o p r o b e s ~}$ for Xanf2 and POMC, respectively. $(J, K, L)$ Lateral view of tailbud stage embryos hybridized with antisense riboprobes for FoxE1, Nkx2.1 and FoxE4 (Xlens1), respectively. Arrowheads denote the position of thyroid expression. (M-O) Section in situ hybridization of st 38 embryos hybridized with antisense probes for FoxE1 $(\mathrm{M}, \mathrm{O})$ or Nkx2.1 (N). (M) Expression of FoxE1 in the thyroid (arrowhead) and pharyngeal endoderm. No expression is observed in the lens (open arrowhead). (N) Expression of FoxE1 in branchial arch mesoderm (arrow) and pharyngeal endoderm. (O) Expression of $\mathrm{Nkx2.1}$ in the thyroid (arrowhead). B, brain; $E$, eye; $H$, heart; $N$, notochord; OV, otic vesicle; $P$, pharynx. endoderm (Fig. 2M,N). Unlike FoxE4, FoxE1 is not expressed in the lens (Fig. 2E-G, M). Thus, even though Foxe1, Foxe3, FoxE1 and FoxE4 are expressed in distinct patterns, the composite expression patterns of the FoxE1 IFoxE4 and Foxe1/Foxe3 gene pairs are similar.

\section{Experimental Procedures}

\section{Isolation of FoxE1 cDNA}

The forkhead domain of FOXE1 was amplified from stage 37 Xenopus laevis embryo head cDNA (prepared using the SMART cDNA Amplification Kit, Clontech) with degenerate primers encoding the amino acids GKPPYSYIA and (D/E)CF(I/V)K(I/V)P. Two sets of primers encoding GKPPYSYIA were mixed together to include all 6 alanine codons. The amplified product was subcloned (TA Cloning Kit, Invitrogen) and sequenced. The sequence was used to design primers for one-armed PCR [(OA-PCR; (Macrae and Brenner, 1994)] using nested FoxE1 primers and 5'- or 3'- SMART primers (SMART cDNAAmplification Kit, Clontech). The sequences of the OA-PCR products were used to design primers to amplify the coding region from the same cDNA. The cDNA sequence was submitted to GenBank (Accession number AY509892). Sequences were aligned using the ClustalW program from the Baylor SearchLauncher Web page:

(URL: http://searchlauncher.bcm.tmc.edu).

\section{In situ hybridization}

Gene expression was analyzed by in situ hybridization using whole embryos (Sive et al., 2000, Turner and Weintraub, 1994) or paraffin sections (Shimamura et al., 1994, Viczian et al., 2003) using digoxigenin-labeled antisense riboprobes.

\section{Acknowledgements}

We thank Paul Krieg and Gerard Martens for sending plasmid DNA, Kathleen Mahon and Shen-Ju Chou for helpful suggestions and comments andrea Viczian for the section in situ hybridization protocol and Carolyn Zilinski for critical reading of the manuscript. This research was sponsored by NIH/NEI grants EY12505 and EY13432 to M.J.

\section{References}

BLIXT, A., MAHLAPUU, M., AITOLA, M., PELTO-HUIKKO, M., ENERBACK, S. and CARLSSON, P. (2000). A forkhead gene, foxe3, is essential for lens epithelial proliferation and closure of the lens vesicle. Genes Dev 14: $245-54$

BROWNELL, I., DIRKSEN, M. and JAMRICH, M. (2000). Forkhead foxe3 maps to the dysgenetic lens locus and is critical in lens development and differentiation. Genesis 27: 81-93.

CARLSSON, P. and MAHLAPUU, M. (2002). Forkhead transcription factors: Key players in development and metabolism. Dev Biol 250: 1-23.

DATHAN, N., PARLATO, R., ROSICA, A., DE FELICE, M. and DI LAURO, $R$. (2002). Distribution of the titf2/foxe1 gene product is consistent with an important role in the development of foregut endoderm, palate and hair. Dev Dyn 224: 450-6.

HISHINUMA, A., OHYAMA, Y., KURIBAYASHI, T., NAGAKUBO, N., NAMATAME, T., SHIBAYAMA, K., ARISAKA, O., MATSUURA, N. and IEIRI, T. (2001). Polymorphism of the polyalanine tract of thyroid transcription factor-2 gene in patients with thyroid dysgenesis. Eur $J$ Endocrinol 145: 385-9.

HOLLEMANN, T. and PIELER, T. (2000). Xnkx-2.1: A homeobox gene expressed during early forebrain, lung and thyroid development in Xenopus laevis. Dev Genes Evol 210: 579-81.

HOLLING, T.M., VAN HERP, F., DURSTON, A.J. and MARTENS, G.J. 
(2000). Differential onset of expression of mrnas encoding proopiomelanocortin, prohormone convertases 1 and 2 and granin family members during Xenopus laevis development. Brain Res Mol Brain Res 75: 70-5.

HROMAS, R. and COSTA, R. (1995). The hepatocyte nuclear factor-3/forkhead transcription regulatory family in development, inflammation and neoplasia. Crit Rev Oncol Hematol 20: 129-40.

KAUFMANN, E. and KNOCHEL, W. (1996). Five years on the wings of fork head. Mech Dev 57: 3-20.

KENYON, K.L., MOODY, S.A. and JAMRICH, M. (1999). A novel fork head gene mediates early steps during Xenopus lens formation. Development 126: 5107-16.

MACRAE, A.D. and BRENNER, S. (1994). One armed pcr (oa-pcr): Amplification of genomic DNA from a single primer domain. Genomics 24: 176-8.

MATHERS, P.H., MILLER, A., DONIACH, T., DIRKSEN, M.L. and JAMRICH, M. (1995). Initiation of anterior head-specific gene expression in uncommitted ectoderm of Xenopus laevis by ammonium chloride. Dev Biol 171: 641-54.

SHIMAMURA, K., HIRANO, S., MCMAHON, A.P. and TAKEICHI, M. (1994). Wnt1-dependent regulation of local e-cadherin and alpha $n$-catenin expression in the embryonic mouse brain. Development 120: 2225-34.

SIVE, H.L., GRAINGER, R.M. and HARLAND, R.M. (2000). Early development of xenopus laevis: A laboratory manual. Cold Spring Harbor Laboratory Press, Cold Spring Harbor, NY.
SMALL, E.M., VOKES, S.A., GARRIOCK, R.J., LI, D. and KRIEG, P.A. (2000). Developmental expression of the Xenopus nkx2-1 and nkx2-4 genes. Mech Dev 96: 259-62.

TURNER, D.L. and WEINTRAUB, H. (1994). Expression of achaete-scute homolog 3 in Xenopus embryos converts ectodermal cells to a neural fate. Genes Dev 8: 1434-47.

VICZIAN, A.S., VIGNALI, R., ZUBER, M.E., BARSACCHI, G. and HARRIS, W.A. (2003). Xotx5b and xotx2 regulate photoreceptor and bipolar fates in the Xenopus retina. Development 130: 1281-94.

YU, J.K., HOLLAND, L.Z., JAMRICH, M., BLITZ, I.L. and HOLLAN, N.D. (2002). Amphifoxe4, an amphioxus winged helix/forkhead gene encoding a protein closely related to vertebrate thyroid transcription factor-2: Expression during pharyngeal development. Evol Dev 4: 9-15.

ZANNINI, M., AVANTAGgIATO, V., BIFFALI, E., ARNONE, M.I., SATO, K., PISCHETOLA, M., TAYLOR, B.A., PHILLIPS, S.J., SIMEONE, A. and DI LAURO, R. (1997). Ttf-2, a new forkhead protein, shows a temporal expression in the developing thyroid which is consistent with a role in controlling the onset of differentiation. EMBO 16: 3185-97.

Received: March 2005

Reviewed by Referees: March 2005

Modified by Authors and Accepted for Publication: March 2005

Edited by: Thomas Sargent 